\title{
¿Estaremos preparados para la siguiente pandemia en México?
}

\section{Will we be prepared for the next pandemic in Mexico?}

\author{
Juan L. Mosqueda-GómeZ* \\ Dirección General, Hospital Regional de Alta Especialidad del Bajío, León, Gto., México
}

En abril del 2009, en México se declaraba el inicio de lo que se convertiría en la última pandemia de influenza de la que habíamos tenido conocimiento. A su término, solo podíamos tener una certeza: una nueva pandemia de virus respiratorios se presentaría en el futuro. La incertidumbre era saber cuándo ocurriría.

La Organización Mundial de la Salud ha alertado permanentemente sobre el riesgo de pandemias causadas por virus respiratorios, haciendo un Ilamado a los países para estar preparados ante esa posibilidad.

Pero, ¿por qué nos preocupan tanto las pandemias de virus respiratorios?

La respuesta es trágica. Basta recordar el número de muertes ocurridas en las pandemias de 1918, 1957 y 1968, siendo la primera la más grave al provocar la muerte, según cálculos, de entre 40 y 100 millones de personas en todo el mundo1,2. Las subsecuentes, de menor magnitud, ocasionaron la muerte de 1 a 2 millones de personas. Por su efecto devastador en la población, nos preocupan estas pandemias.

Se requieren tres cosas para que haya una pandemia causada por un virus respiratorio: 1) que aparezca un subtipo de virus totalmente nuevo, para el que no haya inmunidad entre la población; 2) que ese virus sea capaz de infectar a los humanos, y 3) que se transmita eficientemente de persona a persona.
Comenzamos el año 2020 con la noticia de que en Wuhan, la capital de la provincia de Hubei (en la República Popular China), se habían reportado casos de enfermedad respiratoria causados por un nuevo coronavirus, del que posteriormente supimos que podía causar cuadros respiratorios graves y transmitirse de manera eficiente de humano a humano. Iniciaba el año y aún no lo sabíamos, pero estábamos en el umbral de una nueva pandemia.

En esta ocasión, la cuarta en un periodo de 100 años, se ha identificado al coronavirus 2 del síndrome respiratorio agudo grave (SARS-CoV-2) como el agente etiológico de la enfermedad por coronavirus 2019 (COVID-19), que ha demostrado mayor patogenicidad que el virus de la influenza 11 años atrás, además del agravante de no contar con un fármaco específico para su control.

Al día 11 de junio del 2020, a menos de medio año de iniciada la emergencia sanitaria, se han acumulado en el mundo más de 7.5 millones de casos y oficialmente se han documentado más de 420,000 defunciones ${ }^{3}$.

\section{¿QUÉ HEMOS APRENDIDO DE LAS PANDEMIAS PREVIAS?}

De las pandemias previas deberíamos haber aprendido acerca de prevención, vigilancia epidemiológica y preparación para la atención, pero en realidad solo

\section{Correspondence:}

*Juan L. Mosqueda-Gómez

E-mail: luis.mosqueda@yahoo.com
Date of reception: 01-06-2020

Date of acceptance: 12-06-2020

DOI: 10.24875/HMCM.M20000012
Available online: 09-07-2020 Hosp Med Clin Manag. 2020;13:45-7

2604-0018 / @ 2020 Mexican Regional Hospitals of High Specialty and Federal Hospitals. Published by Permanyer. This is an open access article under the CC BY-NC-ND license (http://creativecommons.org/licenses/by-nc-nd/4.0/). 
hemos actualizado los procedimientos para el aislamiento de personas, y es evidente que nos falta profundizar en el conocimiento de las fuerzas que operan en la propagación de las enfermedades virales respiratorias.

\section{PREVENCIÓN}

Como ya he mencionado, las pandemias del siglo pasado han sido causadas por virus respiratorios, por lo que ya deberíamos haber aprendido estrategias generales de prevención, como: a) la higiene frecuente de manos, ya sea con agua y jabón o con alcohol en gel; b) evitar tocarse la cara, particularmente los ojos, nariz o boca, que son el sitio de entrada de los virus respiratorios, y c) etiqueta respiratoria, que consiste en cubrirse la boca con la parte interna del codo, al toser o al estornudar.

Es importante observar que todas estas recomendaciones se difundieron ampliamente y se implementaron durante la pandemia de influenza AH1N1 en el 2009; sin embargo, al presentarse la actual pandemia estamos nuevamente difundiendo e implementando estas recomendaciones. Es decir, no fueron aprendidas adecuadamente ni quedaron establecidas de forma permanente, como era lo esperado.

En el aspecto de prevención también es importante hablar de la vacunación. Durante la pandemia de influenza AH1N1, como ocurre ahora, se deseaba diseñar una vacuna. Sin embargo, en los años posteriores al 2009, habiendo ya una vacuna disponible, las coberturas de vacunación han sido mucho más bajas de lo deseable, incluso entre el personal de salud. Actualmente, al tiempo que se trabaja en el desarrollo de una vacuna contra el SARS-CoV-2, ya surgen en el mundo movimientos de rechazo hacia esa potencial vacuna. Sin duda, nos falta aún mucho por aprender sobre la importancia que tiene la vacunación en la prevención de enfermedades.

\section{VIGILANCIA EPIDEMIOLÓGICA}

En México se mantiene una vigilancia epidemiológica que nos permite identificar las variaciones en la frecuencia de casos de enfermedades respiratorias durante el año y alertarnos cuando ocurra un incremento inesperado de ellos. Esta vigilancia no debe ser solo numérica, debe estar asociada al diagnóstico específico de una proporción de esos casos, para lo cual debe contarse con laboratorios de biología molecular eficientes y distribuidos en todo el territorio nacional.

Como parte de la respuesta a la pandemia de influenza AH1N1, se fortaleció en México la Red de Laboratorios Estatales de Salud Pública, asegurándose la posibilidad de realizar diagnóstico molecular de enfermedades como influenza y otros virus respiratorios, sarampión, dengue, Zika y chikunguña. Sin embargo, ante esta nueva pandemia nos damos cuenta de que, aunque los laboratorios tienen suficiente capacidad para la vigilancia epidemiológica, tienen limitada capacidad de expansión para responder en el contexto de la COVID-19. Debemos aprender, entonces, que es primordial fortalecer aún más a la red de laboratorios de diagnóstico.

\section{ATENCIÓN MÉDICA}

El mayor problema cuando se presenta una pandemia de virus respiratorios es que ocurre una acumulación excesiva de casos que requieren atención hospitalaria que suele rebasar la capacidad instalada de atención, causando saturación y colapso de los servicios de salud. En la pandemia del 2009 observamos que para brindar la atención necesaria se debía contar con planes para la expansión de las áreas de atención, de manera que se desarrollaron protocolos de reconversión hospitalaria. Desafortunadamente, muchos de esos planes de ampliación y reconversión hospitalaria quedaron elegantemente archivados, pero sin establecerse las condiciones para que pudieran funcionar en caso de necesitarse. La reconversión hospitalaria requiere no solo un plan bien diseñado, sino el respaldo de una reserva estratégica de medicamentos, monitores, ventiladores, equipo de protección personal, entre otros, de manera que pueda implementarse de forma eficiente al ser necesaria.

En esta ocasión debemos aprender adecuadamente y fortalecer esos planes de reconversión y asegurar las reservas estratégicas para su implementación. Adicionalmente, los planes de preparación para una nueva pandemia deben también incluir planes para la comunicación de riesgos, contar con voceros preparados para la difusión adecuada de la información y 
estrategias de distanciamiento social que permitan limitar el número de casos que se presenten.

\section{¿ESTAREMOS PREPARADOS PARA LA SIGUIENTE PANDEMIA?}

Por lo que he mencionado, parece que aún no. Estar preparados para una pandemia no es el trabajo de un año o dos, sino que es un trabajo continuo y permanente; es establecer las condiciones necesarias para responder y asegurar que todo funcione en el momento necesario.

Lo ideal sería realizar simulacros que nos permitan validar la eficacia de nuestros protocolos de respuesta. La influenza nos da esa oportunidad; cada año en México, entre los meses de noviembre y febrero, se presenta la temporada de influenza, lo que nos permitiría hacer un simulacro de lo que vamos logrando. Cada año tenemos oportunidad de hacerlo mejor, para que estemos bien preparados para la siguiente pandemia.

Cada año en temporada de influenza debemos impulsar estrategias de prevención, como el lavado de manos, fomentar la vacunación, evitar la automedicación, evaluar nuestro sistema de vigilancia epidemiológica y probar la capacidad de nuestros planes de reconversión. No sabemos cuándo ocurrirá la siguiente pandemia de virus respiratorios, pero hoy ya falta un día menos para que ocurra.

\section{BIBLIOGRAFÍA}

1. Benítez-Guerra G. Pandemias de influenza. RFM. 2009;32(1):5-6.

2. Taubenberger JK, Morens DM. 1918 Influenza: the mother of all pandemics. Emerg Infect Dis. 2006;12(1):15-22.

3. OMS. Actualización oficial CoViD19 [Internet]. Organización Mundial de la Salud [fecha de consulta 12 de junio 2020]. Disponible en: https://www. who.int/docs/default-source/coronaviruse/situation-reports/20200612-covid-19-sitrep-144.pdf?sfvrsn=66ff9f4f_4 